\title{
Heterozygous inactivating CaSR mutations causing neonatal hyperparathyroidism: function, inheritance and phenotype
}

\author{
Markus Glaudo', Saskia Letz', Marcus Quinkler², Ulrich Bogner², Ulf Elbelt', \\ Christian J Strasburger ${ }^{3}$, Dirk Schnabel ${ }^{4}$, Erwin Lankes ${ }^{4}$, Sandra Scheel ${ }^{5}$, \\ Joachim Feldkamp ${ }^{5}$, Christine Haag ${ }^{6}$, Egbert Schulze ${ }^{6}$, Karin Frank-Raue $^{6}$, \\ Friedhelm Raue ${ }^{6}$, Bernhard Mayr ${ }^{1}$ and Christof Schöfl' \\ ${ }^{1}$ Division of Endocrinology and Diabetes, Department of Medicine I, Universitätsklinikum Erlangen, \\ Erlangen, Germany, ${ }^{2}$ Endokrinologie in Charlottenburg, Berlin, Germany, ${ }^{3}$ Department of Endocrinology, \\ Diabetes and Nutrition, ${ }^{4}$ Center for Chronic Sick Children, Pediatric Endocrinology and Diabetes, \\ Charité - Universitätsmedizin Berlin, Berlin, Germany, ${ }^{5}$ Endocrinology and Diabetology, Klinikum Bielefeld, \\ Bielefeld, Germany, and ${ }^{6}$ Endocrine Practice, Heidelberg, Germany
}

Correspondence should be addressed to B Mayr Email

bernhard.mayr@ uk-erlangen.de

\begin{abstract}
Background: Homozygous inactivating mutations of the calcium-sensing receptor (CaSR) lead to neonatal severe hyperparathyroidism (NSHPT), whereas heterozygous inactivating mutations result in familial hypocalciuric hypercalcemia $(\mathrm{FHH})$. It is unknown why in some cases heterozygous CaSR mutations cause neonatal hyperparathyroidism (NHPT) clinically similar to NSHPT but with only moderately elevated serum calcium. Methods: A literature survey was conducted to identify patients with heterozygous CaSR mutations and NHPT. The common NHPT CaSR mutants R185Q and R227L were compared with 15 mutants causing only FHH in the heterozygous state. We studied in vitro calcium signaling including the functional consequences of co-expression of mutant and wild-type (wt) CaSR, patients' phenotype, age of disease manifestation and mode of inheritance. Results: All inactivating CaSR mutants impaired calcium signaling of wt-CaSR regardless of the patients' clinical phenotype. The absolute intracellular calcium signaling response to physiologic extracellular calcium concentrations in vitro showed a high correlation with patients' serum calcium concentrations in vivo, which is similar in NHPT and FHH patients with the same genotype. Pedigrees of FHH families revealed that paternal inheritance per se does not necessarily lead to NHPT but may only cause FHH.

Conclusions: There is a significant correlation between in vitro functional impairment of the CaSR at physiologic calcium concentrations and the severity of alterations in calcium homeostasis in patients. Whether a particular genotype leads to NHPT or FHH appears to depend on additional predisposing genetic or environmental factors. An individual therapeutic approach appears to be warranted for NHPT patients.
\end{abstract}

European Journal of Endocrinology (2016) 175, 421-431

\section{Introduction}

The calcium-sensing receptor (CaSR) is the key sensor for extracellular calcium $(1,2,3)$. It is expressed mainly in parathyroid tissue, kidney and bone and regulates parathyroid hormone (PTH) secretion and calcium handling in the kidney. The CaSR belongs to class $\mathrm{C}$ of the G protein-coupled receptor superfamily and activates the phospholipase $\mathrm{C}$ - calcium and other signaling pathways (4).

Inactivating mutations of CaSR elevate the set point of receptor activation by extracellular calcium $\left(\left[\mathrm{Ca}^{2+}\right]_{0}\right)$ and
() 2016 European Society of Endocrinology Printed in Great Britain
Published by Bioscientifica Ltd. 


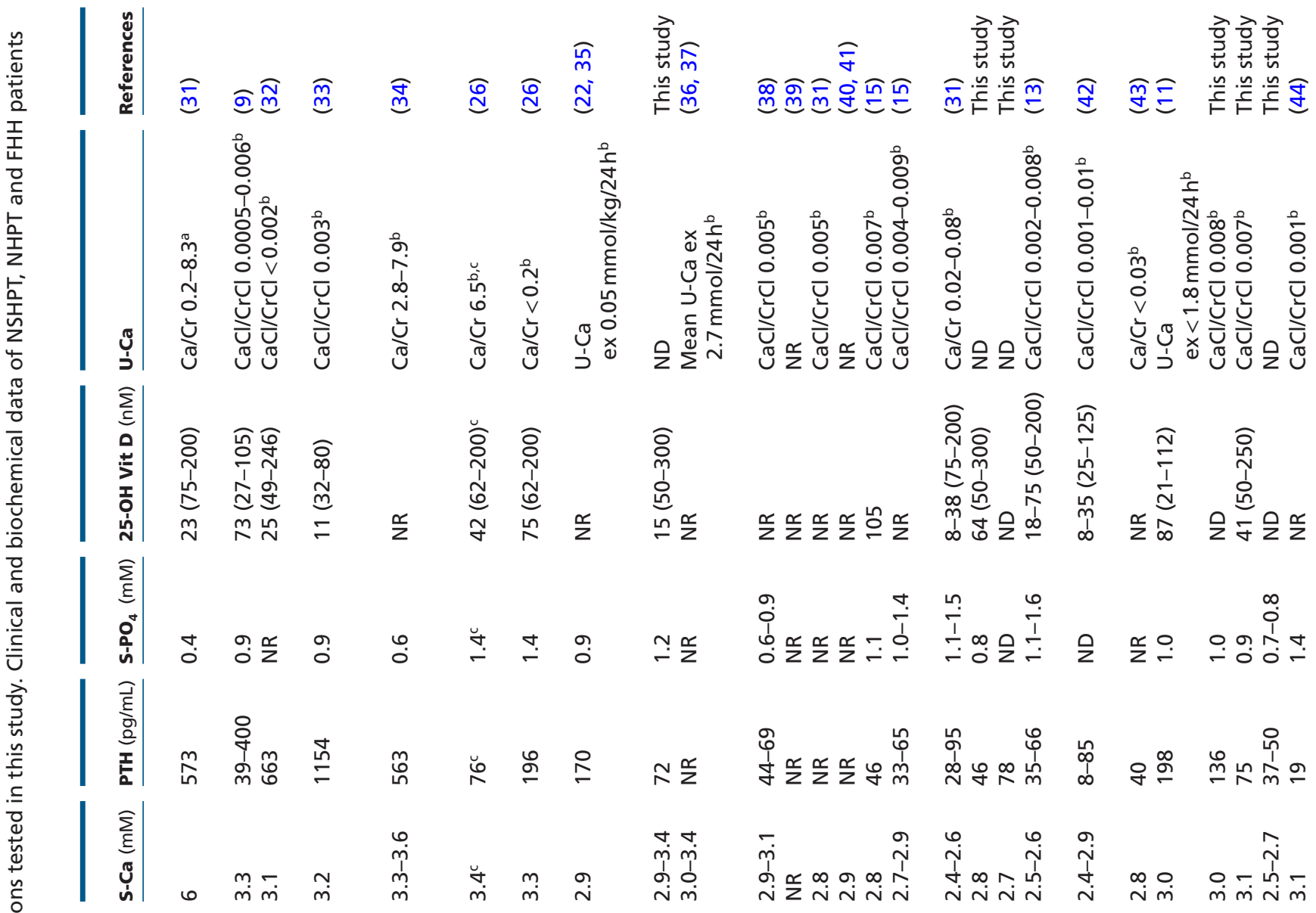
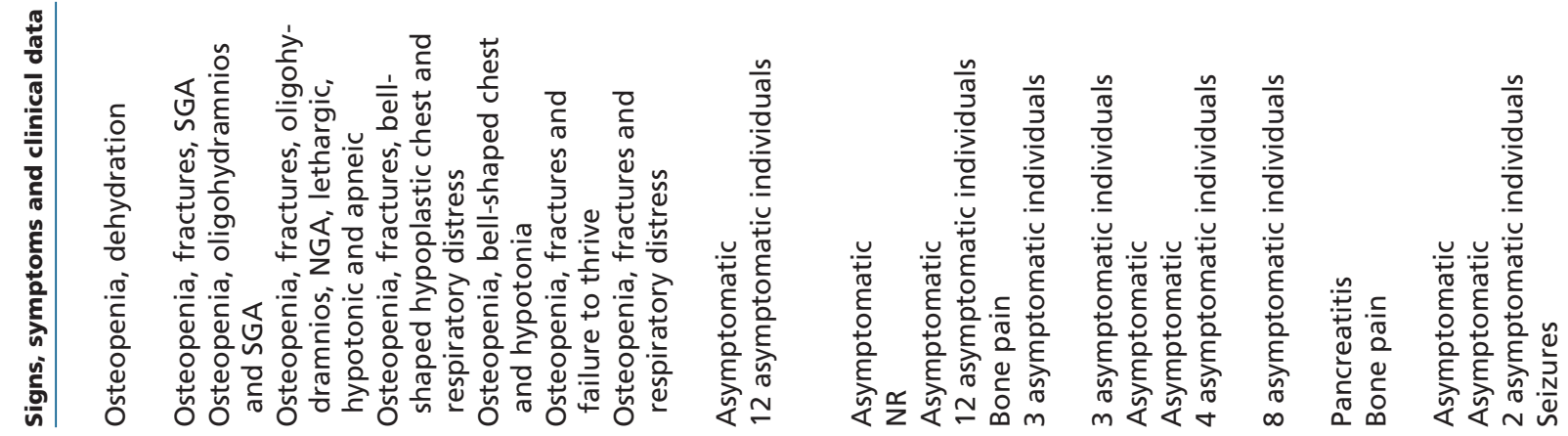

离

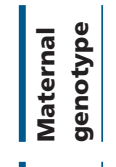

\section{క}

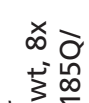

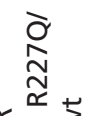

商 항

$\sum_{\substack{n \\ j}}^{n}$

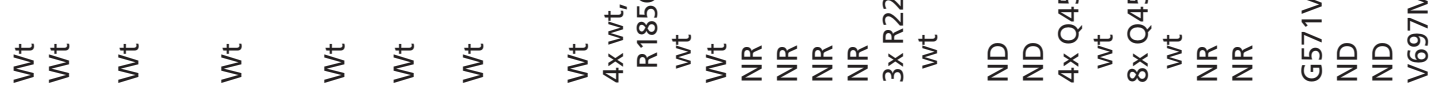

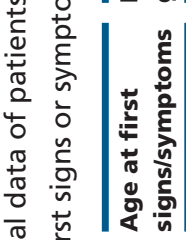

๙
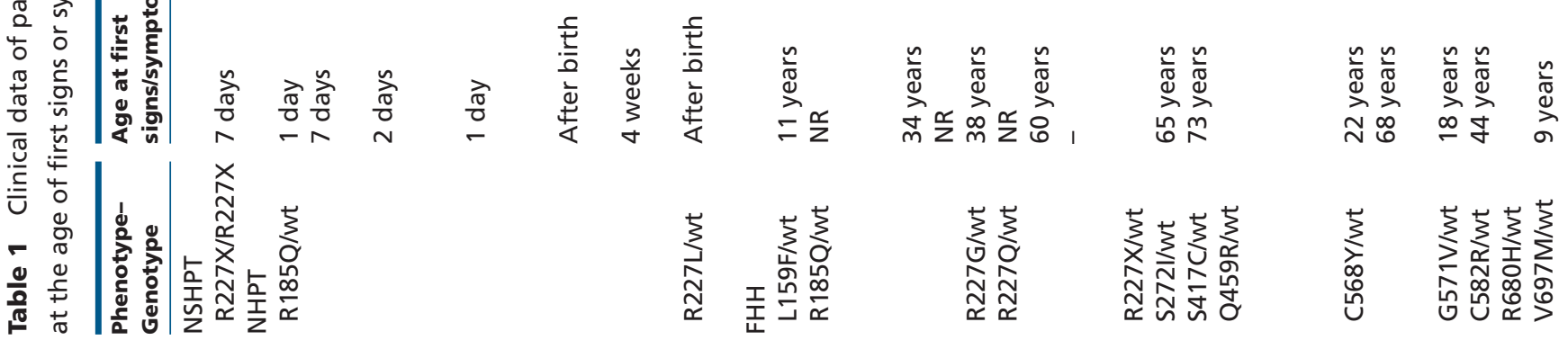

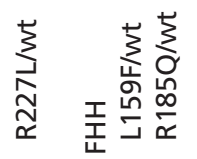

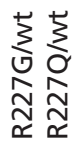

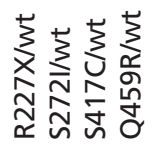

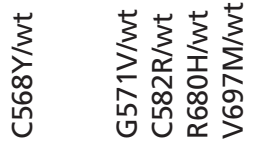




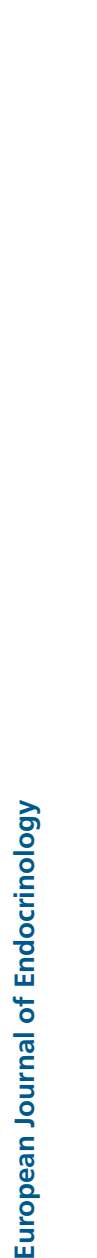

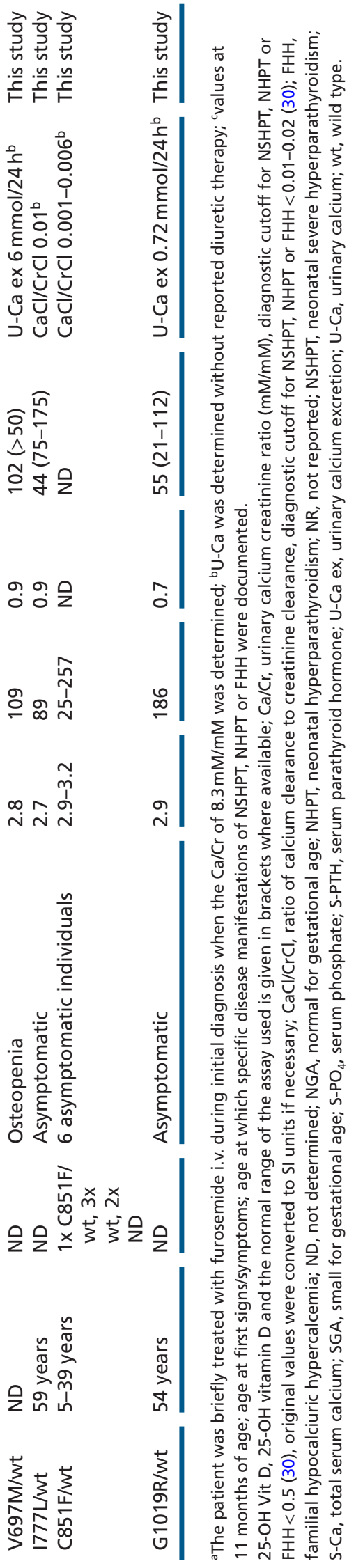

give rise to hypercalcemic disorders such as neonatal severe hyperparathyroidism (NSHPT) caused by homozygous inactivating mutations and the rather benign disease familial hypocalciuric hypercalcemia (FHH) in adults caused by heterozygous inactivating mutations $(1,2,5)$.

However, this clear-cut genotype-phenotype correlation does not hold in several well-documented cases of neonatal hyperparathyroidism, where only one mutated CaSR allele was found (Table 1). In these cases, hypercalcemia with serum calcium levels of around $3 \mathrm{mM}$ was similar to adult patients with the same mutant but only FHH. In contrast, typical patients with neonatal severe hyperparathyroidism (NSHPT) have serum calcium concentrations between 5 and $8 \mathrm{mM}$ (Table 1 and $(5,6$, $7,8)$ ). The milder form of neonatal hyperparathyroidism is therefore more appropriately called NHPT (neonatal hyperparathyroidism).

Although the total or near-total loss of CaSR function in homozygous patients readily explains the severe biochemical and clinical phenotype in NSHPT, it is unclear why heterozygous CaSR mutations in some cases lead to serious clinical problems shortly after birth (NHPT), whereas in majority of patients no or only minor symptoms exist in adults (FHH).

One explanation proposed is that in NHPT, the mutated CaSR protein has a negative effect on the wild-type (wt) CaSR transcribed from the remaining normal allele, which results in impaired CaSR signaling in cells expressing both mutant and wt-CaSR $(1,9)$. An alternative explanation attributed the NHPT phenotype to a paternally inherited or de novo CaSR mutant. This leads to the unique situation of a fetus with an impaired CaSR function developing in a maternal environment with a normal CaSR $(9,10)$.

Neither hypothesis about the pathophysiology of NHPT has been comprehensively tested by studying functional impairment and negative effects of CaSR mutants on wt-CaSR in vitro, the mode of inheritance and the clinical phenotype in vivo.

\section{Subjects and methods}

\section{Patients and mutants}

A literature search was performed to identify CaSR mutants that can cause NHPT in the heterozygous state. We chose the mutants R185Q and R227L for further in vitro analyses because there are six documented cases of NHPT with a heterozygous R185Q mutation and the amino acid R227 offered the possibility to study an NHPT mutant (R227L) 
in comparison with point and truncation mutants at the same position that cause FHH (R227G, R227Q and R227X) (Table 1). For additional comparison, we selected CaSR mutants from published reports and our own FHH patients where a complete history and biochemical workup was available to assess the clinical phenotype and its time of manifestation. Patients' family history and genetic studies were reviewed to determine the mode of inheritance of the CaSR mutation. This study was performed according to the Bavarian state law (Bayerisches Krankenhausgesetz/Bavarian Hospital Law Art. 27 paragraph 4) that allows the use of patient data for research, provided that any person's related data are kept anonymous. In addition, this study was also examined by a local ethics committee, and a written statement was provided verifying that no ethics committee review was required for this study and that there were no concerns regarding its publication.

\section{Functional analyses of CaSR function}

Expression plasmids for wt-CaSR and 17 mutants from patients with NSHPT, NHPT and FHH (Table 1) were generated by site-directed mutagenesis, confirmed by sequencing and expressed in HEK 293T cells cultured on glass coverslips as described before $(11,12$, $13,14)$. One microgram CaSR expression vector or, for co-transfection experiments, $0.5 \mu \mathrm{g}$ mutant CaSR and $0.5 \mu \mathrm{g}$ YFP-tagged wt-CaSR were used for transient transfection. Transiently transfected HEK 293T cells were loaded with $5 \mu \mathrm{M}$ Fura-2/AM (Invitrogen), placed in superfusion buffer and used for measurements of cytosolic free calcium $\left(\left[\mathrm{Ca}^{2+}\right]_{\mathrm{i}}\right)$ by dual-wavelength excitation microfluorometry. Dose-response curves were carried out as described $(11,12,13,14)$. Protein expression was analyzed by Western blotting (Supplementary Methods and Supplementary Fig. 1, see section on supplementary data given at the end of this article).

\section{Statistical analysis}

Nonlinear regression of dose-response curves was performed with GraphPad Prism 6 (GraphPad) using $\Delta\left[\mathrm{Ca}^{2+}\right]_{\mathrm{i}}$ values. $\mathrm{EC}_{50}$ values, maximum $\Delta\left[\mathrm{Ca}^{2+}\right]_{\mathrm{i}}$ response and $95 \%$ confidence intervals were determined from the nonlinear regression curves $(12,14)$. The regression fits of wt and mutant/wt-CaSR were tested for statistically significant differences with an F-test using GraphPad Prism 6 (GraphPad) by comparing two nested models as described (14). In the first model, the parameters $\mathrm{EC}_{50}$ or maximum $\Delta\left[\mathrm{Ca}^{2+}\right]_{\mathrm{i}}$ response were common for both wt and mutant CaSR, and in the second model, these parameters were allowed to be different.

Linear correlation analyses of average serum calcium levels in heterozygous patients without prior parathyroidectomy or cinacalcet or bisphosphonate therapy (taken from Table 1) against in vitro parameters were performed by calculating the Pearson productmoment correlation coefficient $(r)$ using Microsoft Excel 2012 (Microsoft). In vitro parameters used were the $\mathrm{EC}_{50}$ and the maximum $\Delta\left[\mathrm{Ca}^{2+}\right]_{\mathrm{i}}$ of the dose-response curves for $\left[\mathrm{Ca}^{2+}\right]_{\mathrm{O}}$-induced changes in $\left[\mathrm{Ca}^{2+}\right]_{\mathrm{i}}$, as well as the absolute $\Delta\left[\mathrm{Ca}^{2+}\right]_{\mathrm{i}}$ at every $\left[\mathrm{Ca}^{2+}\right]_{\mathrm{o}}$ from 0.5 to $30 \mathrm{mM}$ at $0.1 \mathrm{mM}$ intervals (derived from dose-response curves shown in Fig. 1). Results were confirmed using SigmaPlot version 11.0 (Systat, Erkrath, Germany).

\section{Results}

\section{Mutant CaSR attenuates wt-CaSR-induced calcium signaling in vitro}

The NSHPT mutant R227X showed no increase in $\left[\mathrm{Ca}^{2+}\right]_{\mathrm{i}}$ in response to stimulation with $\left[\mathrm{Ca}^{2+}\right]_{0}$ as expected (Supplementary Fig. 1, solid lines). By contrast, the NHPT mutants R185Q and R227L showed less severe signaling impairment with marked shifts of $\mathrm{EC}_{50}$ for extracellular calcium $\left[\mathrm{Ca}^{2+}\right]_{0}$ to the right but no decrease in maximum $\left[\mathrm{Ca}^{2+}\right]_{\mathrm{i}}$ response (Supplementary Fig. 1, solid lines, and Table 2). All mutants from FHH patients showed an impaired signaling function with increases in $\mathrm{EC}_{50}$ and/or a reduction of the maximal $\left[\mathrm{Ca}^{2+}\right]_{\mathrm{i}}$ response (Table 2 ).

Co-expression of most CaSR mutants with wt-CaSR (Fig. 1, dashed lines) resulted in an increase in the $\mathrm{EC}_{50}$ for $\left[\mathrm{Ca}^{2+}\right]_{0}$-induced changes in $\left[\mathrm{Ca}^{2+}\right]_{\mathrm{i}}$ and/or a decrease in the maximum $\left[\mathrm{Ca}^{2+}\right]_{\mathrm{i}}$, response compared with wt-CaSR alone. This indicates a dominant-negative effect of the CaSR mutants on wt-CaSR (Table 2). Most interestingly, however, the two NHPT mutants R185Q and R227L behaved differently. Co-expression of R185Q with wt-CaSR did neither affect the $\mathrm{EC}_{50}$ nor the maximum $\left[\mathrm{Ca}^{2+}\right]_{\mathrm{i}}$ signaling response, and co-expression of $\mathrm{R} 227 \mathrm{~L}$ only caused a small right shift of the dose-response curve and actually seemed to enhance the maximum $\left[\mathrm{Ca}^{2+}\right]_{i}$ response of wt-CaSR (Table 2).

A closer look at the dose-response curves at $\left[\mathrm{Ca}^{2+}\right]_{0}$ below $3 \mathrm{mM}$, which is approximately in the physiologic in vivo range, revealed that the $\left[\mathrm{Ca}^{2+}\right]_{0}-$ induced $\left[\mathrm{Ca}^{2+}\right]_{\mathrm{i}}$ increase was clearly attenuated. 

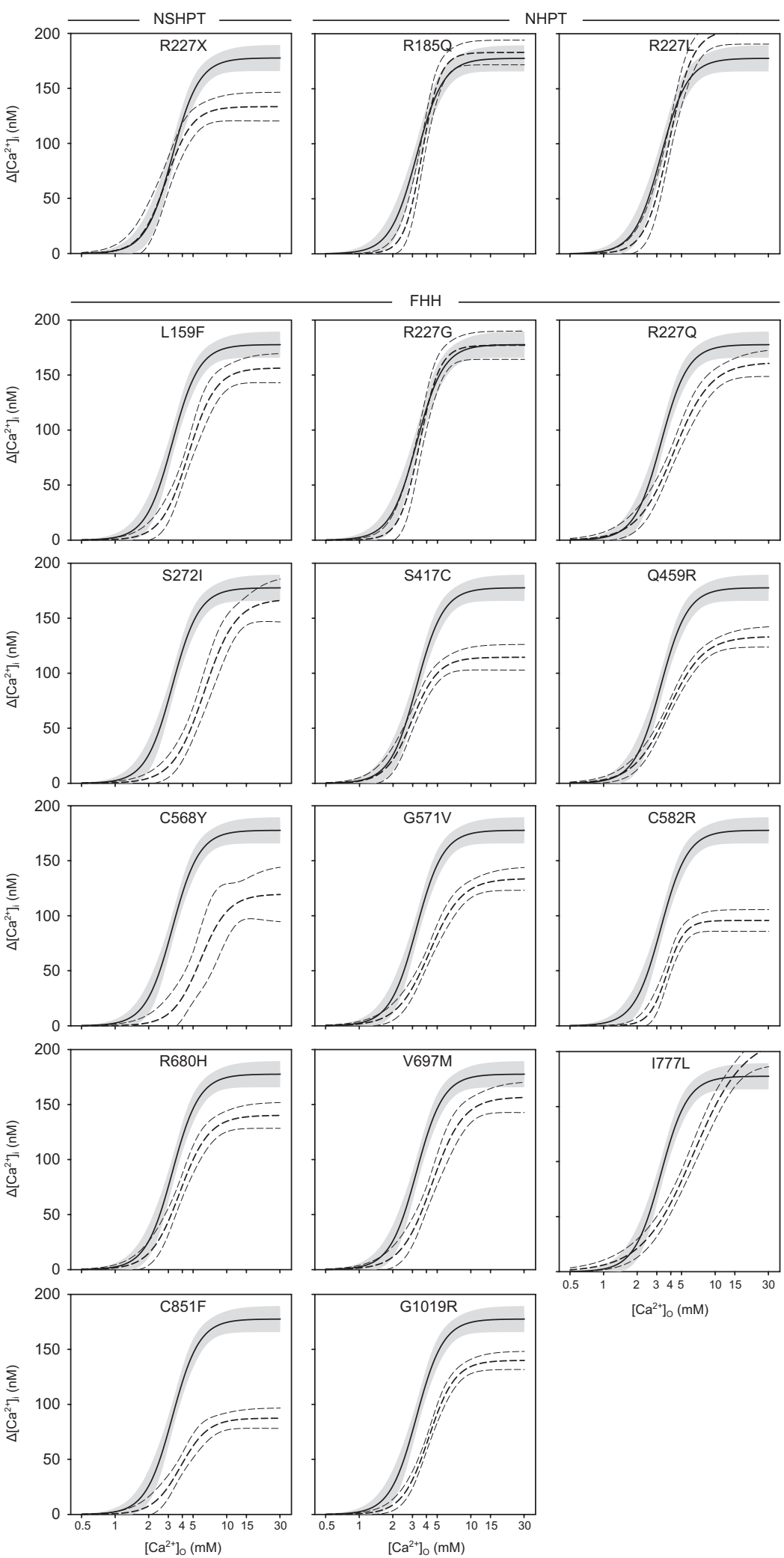

$\left[\mathrm{Ca}^{2+}\right]_{0}(\mathrm{mM})$

\section{Figure 1}

Intracellular free calcium $\left[\mathrm{Ca}^{2+}\right]_{i}$ signaling function and effects on wt-CaSR of 17 inactivating CaSR mutants causing NSHPT, NHPT or $\mathrm{FHH}$. Dose-response curves $( \pm 95 \%$ confidence interval) of $\Delta\left[\mathrm{Ca}^{2+}\right]_{i}$ in response to a stepwise increase of $\left[\mathrm{Ca}^{2+}\right]_{0}$ for wt-CaSR (solid line with gray confidence interval) and wt-CaSR co-expressed with mutant (dashed lines). Results from eight to 50 individual HEK-293T cells from at least three independent experiments are shown.
There was hardly any overlap of the 95\% confidence intervals in cells co-expressing wt-CaSR and the R185Q CaSR mutant compared with cells expressing wt-CaSR only (Fig. 1, dashed lines vs gray, confidence interval of the wild type). A similar impairment in cytosolic calcium signaling at low $\left[\mathrm{Ca}^{2+}\right]_{0}$ was observed when wt-CaSR was 
Table 2 Effects on wt-CaSR function of 17 inactivating CaSR mutants causing different clinical phenotypes.

\begin{tabular}{|c|c|c|c|c|}
\hline \multirow{2}{*}{$\begin{array}{l}\text { Phenotype } \\
\text { Genotype } \\
\end{array}$} & \multicolumn{2}{|c|}{ Mutant or wt } & \multicolumn{2}{|c|}{ Mutant and wt co-expressed } \\
\hline & $\mathrm{EC}_{50}(\mathrm{mM})$ & Max response $(\mathrm{nM})$ & $\mathrm{EC}_{50}(\mathrm{mM})$ & Max response $(\mathrm{nM})$ \\
\hline \multicolumn{5}{|l|}{ Normal } \\
\hline Wt & $3.3(3-3.6)$ & $178(166-190)$ & & \\
\hline \multicolumn{5}{|l|}{ NSHPT } \\
\hline $\mathrm{R} 227 \mathrm{X}^{\mathrm{a}}$ & $2.5(1.2-5.4)$ & $8.6(6.15-11.1)$ & $2.9(2.5-3.3) \mathrm{NS}$ & $133(120-147) * * *$ \\
\hline \multicolumn{5}{|l|}{ NHPT } \\
\hline $\mathrm{R} 185 \mathrm{Q}^{\mathrm{b}}$ & $17.5(14-22)$ & $181(138-224)$ & $3.7(3.4-3.9) \mathrm{NS}$ & $183(172-194)$ NS \\
\hline $\mathrm{R} 227 \mathrm{~L}$ & $8.4(7.5-9.4)$ & $231(212-250)$ & $3.9(3.6-4.2) * *$ & $203(191-216) * *$ \\
\hline \multicolumn{5}{|l|}{$\mathrm{FHH}$} \\
\hline L159F & $8.8(7.9-9.8)$ & $174(158-189)$ & $4.6(4.1-5.1) * * *$ & $156(143-170)$ NS \\
\hline R227G & $8.1(6.8-9.7)$ & $199(173-224)$ & $3.5(3.2-3.8) \mathrm{NS}$ & 177 (164-190) NS \\
\hline $\mathrm{R} 227 \mathrm{Q}$ & $4.7(4.0-5.4)$ & $151(136-167)$ & $4.3(3.8-4.8) * *$ & $162(149-175) \mathrm{NS}$ \\
\hline S272I & $46.3(6.9-310)$ & $356(-200$ to 913$)$ & $6.3(5.2-7.7) * * *$ & 167 (146-189) NS \\
\hline S417C & $5(4.5-5.5)$ & $109(100-117)$ & $3.0(2.6-3.3) \mathrm{NS}$ & $115(103-126) * *$ \\
\hline Q459R & $3.9(3.4-4.5)$ & $125(111-139)$ & $3.8(3.5-4.2)^{*}$ & $133(124-143) * * *$ \\
\hline C568Y & $6.7(4.4-10.1)$ & $7(5.4-8.7)$ & $5.8(4.1-8.3)^{*}$ & $120(93-146)^{*}$ \\
\hline G571V & $4.3(3.9-4.7)$ & $124(111-136)$ & $4.3(3.8-4.8) * *$ & $134(123-145) * * *$ \\
\hline C582R & $15.2(0.2-946)$ & $14(-6.5$ to 34.5$)$ & $3.7(3.4-4.0) \mathrm{NS}$ & $96(86-106)^{* *}$ \\
\hline $\mathrm{R} 680 \mathrm{H}$ & $4.7(4.3-5.0)$ & $109(102-116)$ & $3.8(3.4-4.3)$ NS & $140(128-152) *$ \\
\hline V697M & $6.1(5.3-7.1)$ & 163 (148-177) & $4.5(4.0-5.1) * * *$ & 157 (142-171) NS \\
\hline 1777L & $5.2(4.3-6.2)$ & 177 (154-199) & $6.4(5.2-7.9) * * *$ & $214(187-242) \mathrm{NS}$ \\
\hline $\mathrm{C} 851 \mathrm{~F}$ & $9(6.9-11.7)$ & $89(73-106)$ & $3.9(3.4-4.5)$ NS & $87(78-97) *$ \\
\hline G1019R & $3.7(3.4-4.0)$ & $134(125-144)$ & $4.2(3.9-4.5) * * *$ & $140(132-148) * * *$ \\
\hline
\end{tabular}

$\mathrm{EC}_{50}$, extracellular calcium concentration giving half maximal response; max response; maximal response defined as the top plateau of the dose-response curve determined in the nonlinear regression analysis. $95 \%$ confidence intervals are given in brackets. The $P$ values for the regression fit was obtained by comparing nested models with $\mathrm{EC}_{50}$ and maximum response common between mutant co-expressed with wild type and wild type or allowed to be different. ${ }^{*} P<0.05 ;{ }^{*} P<0.01 ; * * * P<0.001$; NS, not significant; ${ }^{a}$ R227X/wt causes FHH (Table 1); ${ }^{b}$ R185Q/wt can also cause FHH (Table 1).

co-expressed with the other NHPT mutant R227L. The FHH mutants R227G and R227Q also attenuated the wt-CaSR cytosolic calcium response at low extracellular calcium. By contrast, the truncated CaSR mutant R227X, which in the heterozygous state barely leads to a rise in serum calcium level in affected patients (Table 1), did not seem to affect the wt-CaSR-induced cytosolic calcium response at $\left[\mathrm{Ca}^{2+}\right]_{0}$ below $4 \mathrm{mM}$ (Fig. 1, dashed lines). This suggests a relationship between the $\left[\mathrm{Ca}^{2+}\right]_{0}$-induced absolute $\left[\mathrm{Ca}^{2+}\right]_{\mathrm{i}}$ increases at lower $\left[\mathrm{Ca}^{2+}\right]_{0}$ in vitro with in vivo serum calcium levels measured in patients.

\section{$\left[\mathrm{Ca}^{2+}\right]_{0}$-induced calcium signaling in vitro correlates with serum calcium in vivo}

To explore a possible relationship between the $\left[\mathrm{Ca}^{2+}\right]_{0}-$ induced cytosolic calcium response in vitro with in vivo serum calcium in heterozygous patients, a linear correlation analyses was performed for all 17 CaSR mutants co-expressed with wt-CaSR. In vitro parameters used were the $\mathrm{EC}_{50}$ and the maximum $\Delta\left[\mathrm{Ca}^{2+}\right]_{\mathrm{i}}$ of the dose-response curves for $\left[\mathrm{Ca}^{2+}\right]_{\mathrm{o}}$-induced changes in $\left[\mathrm{Ca}^{2+}\right]_{\mathrm{i}}$, as well as the absolute $\Delta\left[\mathrm{Ca}^{2+}\right]_{\mathrm{i}}$ at $\left[\mathrm{Ca}^{2+}\right]_{\mathrm{o}}$ ranging from 0.5 to $30 \mathrm{mM}$. The Pearson product-moment correlation coefficient (r) was $0.228(P=0.36)$ for serum calcium and $\mathrm{EC}_{50}$ and $-0.147(P=0.56)$ for serum calcium and maximum $\Delta\left[\mathrm{Ca}^{2+}\right]_{\mathrm{i}}$ response. By contrast, the correlation between serum calcium in vivo and the cytosolic calcium response at different $\left[\mathrm{Ca}^{2+}\right]_{\mathrm{o}}$ peaked at $2.0 \mathrm{mM}\left[\mathrm{Ca}^{2+}\right]_{\mathrm{o}}$ with a $r$ value of -0.829 ( $P=0.000022)$ (Fig. 2A). This indicates a highly significant negative correlation of patients' in vivo serum calcium levels with the in vitro ability to activate cytosolic calcium signaling in response to $\left[\mathrm{Ca}^{2+}\right]_{\mathrm{O}}$ in the physiologic range. Accordingly, patients heterozygous for the R185Q CaSR mutation had high serum calcium levels, whereas patients heterozygous for R227X CaSR had only mildly elevated serum calcium levels (Fig. 2B). Remarkably, there is no apparent difference between NHPT and non-NHPT mutants. This demonstrates a strong link between the functional impairment of the CaSR to activate the calcium signaling pathway in vitro and in vivo calcium homeostasis in patients regardless of clinical phenotype.

\section{Paternal inheritance per se does not cause NHPT}

There are reports about 14 patients with a heterozygous R185Q CaSR mutation, who had no neonatal symptoms (Table 1). This clearly demonstrates that additional 

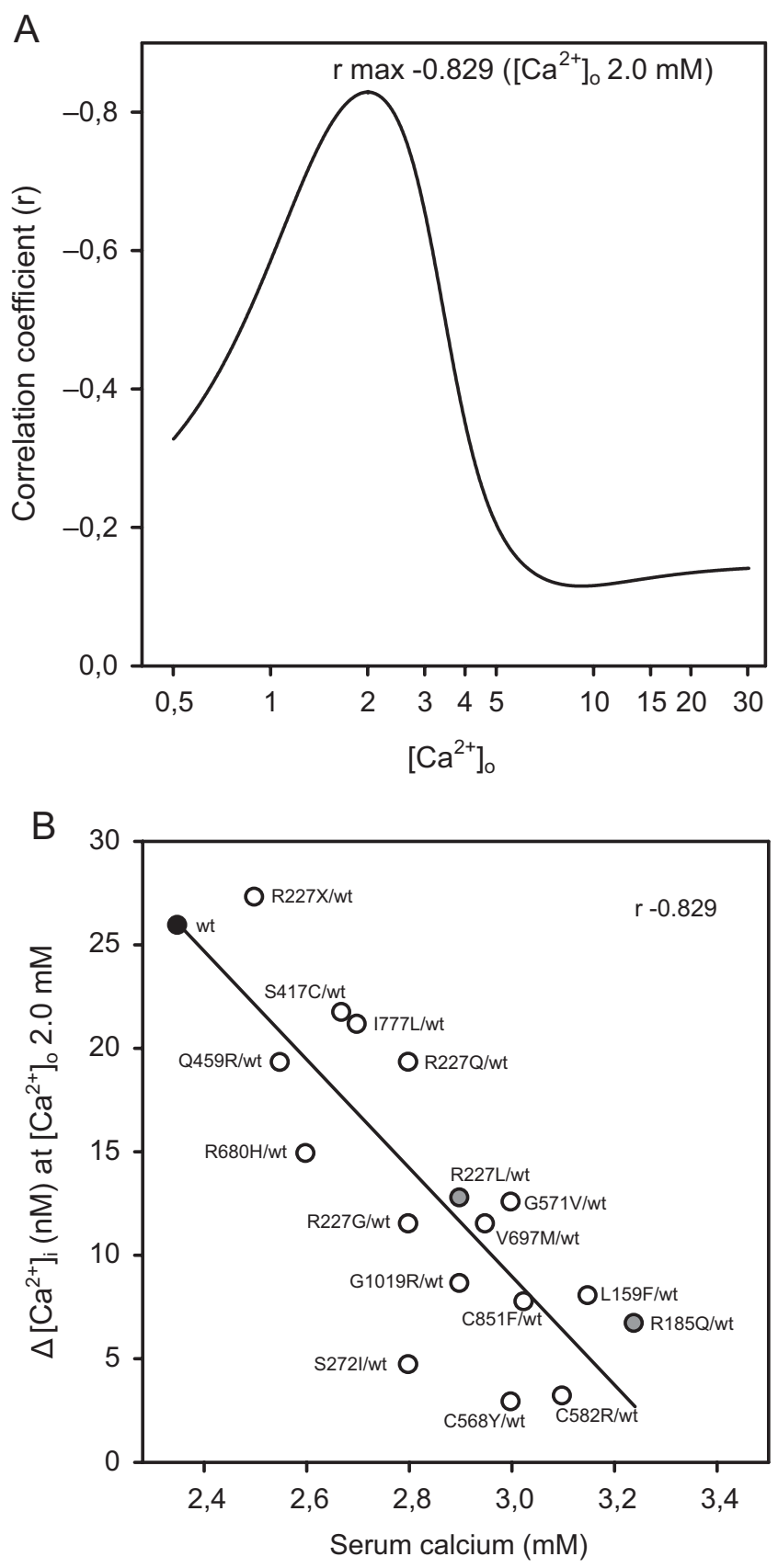

Figure 2

Relationship between CaSR-activated cytosolic calcium signaling in vitro and serum calcium levels in vivo. Correlation analysis of average serum calcium levels against absolute cytosolic calcium responses $\left(\Delta\left[\mathrm{Ca}^{2+}\right]_{\mathrm{i}}\right)$ of all $17 \mathrm{CaSR}$ mutants co-expressed with wt-CaSR. Average serum calcium concentrations were calculated from patients shown in Table 1 and the midpoint of the reference range of serum calcium (2.1-2.6 mM) of $2.35 \mathrm{mM}$ was used for wt-CaSR. Absolute cytosolic calcium responses in vitro $\left(\Delta\left[\mathrm{Ca}^{2+}\right]_{\mathrm{i}}\right)$ at in vitro $\left[\mathrm{Ca}^{2+}\right]_{0}$ from 0.5 to $30 \mathrm{mM}$ at $0.1 \mathrm{mM}$ intervals were derived from factors exist, which determine the clinical phenotype and its time of manifestation. We reviewed our patient's family histories in order to assess the impact of paternal inheritance or de novo mutation (Table 1). In two families, we identified a total of four subjects harboring heterozygous CaSR mutations, who were born to mothers with wt-CaSR (Fig. 3). None of the four individuals (one with a L159F/wt and three with a C851F/wt genotype) had clinical symptoms as neonates. They presented as asymptomatic FHH with rather high serum calcium levels and were diagnosed between the age of 11 and 39 years because of family screening or routine blood tests. Both, the L159F and the C851F CaSR mutant, caused a similar impairment of the cytosolic calcium response at $2.0 \mathrm{mM}\left[\mathrm{Ca}^{2+}\right]_{\mathrm{o}}$ as the $\mathrm{R} 185 \mathrm{Q}$ mutant when co-expressed with wt-CaSR (Fig. 2B). This demonstrates that paternal inheritance per se does not necessarily lead to NHPT.

\section{Discussion}

\section{Genotype, function and phenotype}

NHPT patients with symptomatic hyperparathyroidism shortly after birth contradict the paradigm that heterozygous CaSR mutations cause rather mild or asymptomatic FHH phenotypes in adults and that a homozygous CaSR mutation is required for a neonatal phenotype. This apparent exception from the genotypephenotype relationship has been attributed to a dominantnegative effect of CaSR mutants causing NHPT on the wt-CaSR $(1,9)$. Consistently, the R185Q and R227L CaSR mutants impaired wt-CaSR-dependent cytosolic calcium signaling as described previously $(9,15)$.

However, each of the 15 mutants we tested, which cause only a FHH phenotype in adults, leads to an even more severe alteration of wt-CaSR-dependent cytosolic calcium signaling with lower maximum $\left[\mathrm{Ca}^{2+}\right]_{\mathrm{i}}$ responses and higher $\mathrm{EC}_{50}$ values. Furthermore, there was no correlation between the $\mathrm{EC}_{50}$ values or the maximum cytosolic calcium responses with serum calcium concentrations in vivo. Thus, the assumption that

dose-response curves shown in Fig. 1. (A) Pearson productmoment correlation coefficient $(r)$ at different in vitro $\left[\mathrm{Ca}^{2+}\right]_{0}$; $r$ max, highest $r$ value. (B) Individual regression analysis at $\left[\mathrm{Ca}^{2+}\right]_{0}$ of $2.0 \mathrm{mM}$ with the highest $r$. NHPT mutants R185Q and $\mathrm{R} 227 \mathrm{~L}$ are indicated by gray circles, wt-CaSR is shown as a black circle. 
A

I

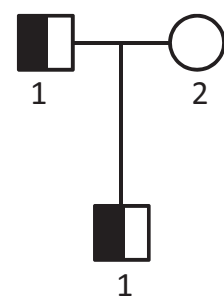

B

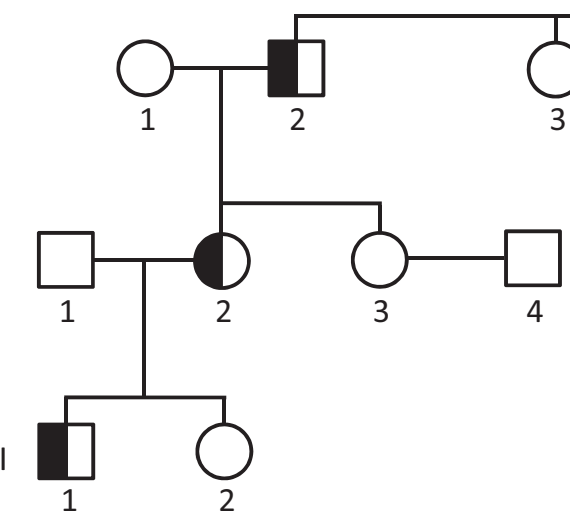

5

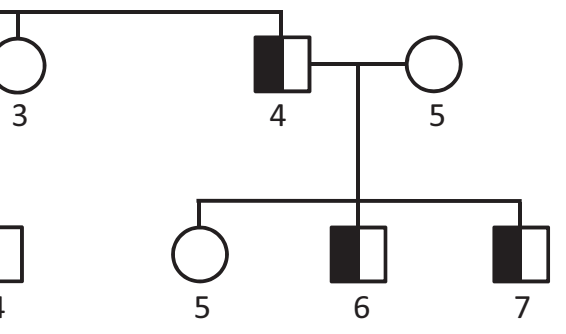

parameters of overall impairment of CaSR-dependent cytosolic calcium signaling could be associated with the clinical phenotype appears to be misleading. However, there was a highly significant correlation between the $\left[\mathrm{Ca}^{2+}\right]_{0}$-induced cytosolic calcium response in the physiologic range in vitro and the in vivo serum calcium levels. For example, expression of the CaSR mutants R185Q and R227L strongly attenuate wt-CaSR cytosolic calcium signaling at $2 \mathrm{mM}\left[\mathrm{Ca}^{2+}\right]_{\mathrm{o}}$ and leads to higher serum calcium levels in affected patients compared with CaSR mutants such as R227X, S417C or I777L that inhibit wt-CaSR-dependent calcium signaling only at higher $\left[\mathrm{Ca}^{2+}\right]_{0}$ (Fig. 1). The observed correlation at low $\left[\mathrm{Ca}^{2+}\right]_{0}$ appears to explain most of the changes in the calcium metabolism in affected patients. Thus, a function-phenotype model appears to predict the clinical disturbances of the calcium homeostasis in NHPT and FHH patients better than a simple genotypephenotype model.

The finding that the vast majority of inactivating CaSR mutants negatively affects wt-CaSR signaling function fits well into this concept. Loss of one CaSR allele leads to only mild FHH in mice (16), and it has been noticed before that FHH patients with mutants that completely abolish protein expression from one allele tend to have lower serum calcium levels compared with $\mathrm{FHH}$ patients that express a functionally impaired CaSR protein (17). This is also nicely illustrated by the in vitro and in vivo differences observed between truncation and point mutations occurring at the same amino acid. Patients with the CaSR truncation mutants R227X and R185X have lower serum calcium levels than those with R227G, Q, L or R185Q mutants (Table 1 and (18)). A dominant-negative impact of mutant CaSR has been previously suspected to underlie elevated serum calcium levels in FHH patients $(15,17)$, and this notion is clearly supported by our results.

\section{Homeostasis and clinical severity}

In FHH and NSHPT, there is a good correlation between alterations in calcium metabolism and the overall clinical severity. FHH patients have moderately elevated serum calcium levels and are mostly asymptomatic, whereas homozygous NSHPT patients have grossly elevated serum calcium concentrations and are critically ill. In contrast, NHPT and FHH patients have very similar serum calcium levels, particularly those with the same heterozygous mutations. The mutant R185Q is by far the most frequent mutation in NHPT patients reported so far with six published cases. There are, however, four reports with a total of 14 patients harboring the same genotype but presenting as FHH (Table 1). R185Q/wt patients with NHPT have serum calcium levels between 3.1 and $3.6 \mathrm{mM}$ and R185Q/wt patients with FHH between 2.9 and $3.4 \mathrm{mM}$ (Table 1). NHPT patients with heterozygous mutations in other amino acids have serum calcium levels between 2.8 and $3.2 \mathrm{mM}$, whereas typical homozygous NSHPT patients have serum calcium levels between 5 and $8 \mathrm{mM}$ (Table 1 and $(5,6,7,8))$. In fetuses and neonates with heterozygous CaSR mutations, the alteration of calcium homeostasis and the overall severity of the clinical phenotype can obviously be dissociated. 


\section{Inheritance}

Paternal inheritance or a de novo CaSR mutation has been suggested as one possible explanation for the development of NHPT $(9,10)$. In this and in previous studies, however, neonates with heterozygous CaSR mutations born to mothers with wt-CaSR did not develop NHPT (Fig. 3 and Table 1). Nevertheless, it is noteworthy that none of the published cases of heterozygous NHPT was born to a mother with a mutated CaSR (Table 1, (19, $20,21,22)$ ). Thus, paternal inheritance or a de novo CaSR mutation does not cause NHPT per se, but there may be genetic factors such as allelic imbalance that predispose or contribute to the risk for NHPT.

\section{Calcium and vitamin D supply}

Metabolic bone disease and osteopenia are a clinical hallmark of NHPT (Table 1 and $(19,20,23))$. During fetal development, calcium is exclusively supplied by the mother via active placental transport that is stimulated by fetal PTH-related peptide (PTHrP) but not by maternal or fetal PTH (24). PTHrP is highly expressed in murine fetal parathyroid glands and its secretion seems to be regulated through CaSR-dependent mechanism, as in CaSR knockout fetuses plasma PTHrP levels as well as placental calcium transport are reduced (25). If in humans the same regulatory mechanisms exist, impaired CaSR activity would cause decreased PTHrP expression and reduced calcium supply to the fetus. The resulting fetal calcium deficiency can lead to secondary hyperparathyroidism, which is exaggerated by the elevated calcium set point due to the inactivating CaSR mutant. Both low calcium and high PTH promote clinically significant metabolic bone disease. A similar pathomechanism has been observed in a young FHH patient with rickets due to pronounced calcium and vitamin D deficiency (13). In NHPT patients, vitamin D deficiency is common (Table 1 and $(19,20,23)$ ), and as in FHH patients, sufficient calcium and vitamin D supply reduces PTH and improves metabolic bone disease $(13,20)$. By contrast, calcium restriction can lead to a further rise in PTH and a lack of clinical improvement (26). This model of calcium deficiency and an exaggerated secondary hyperparathyroidism explains quite well the observed pathologic changes in NHPT patients. Further support is provided by several cases, in which NHPT was self-limited under supportive care and normal nutrition despite stable (27) or even slightly rising $(21,28,29)$ serum calcium levels. According to this concept, NHPT may develop if the combined effects of impairment of wt-CaSR function by the mutant and of additional environmental or genetic factors that reduce maternal calcium supply to the fetus reach a critical threshold. This could also explain the variable phenotype in patients heterozygous for the R185Q CaSR mutant, but direct effects of the mutant CaSR on chondrocytes and osteoblasts may also contribute to the phenotype.

\section{Summary}

Taken together, there is a strong and highly significant correlation between functional impairment of CaSRdependent calcium signaling and patients' serum calcium levels. Patients with complete or near-complete loss of CaSR signaling, for example, due to severely inactivating homozygous CaSR mutations develop NSHPT with excessive PTH secretion that is not suppressed by even grossly elevated serum calcium levels. In contrast, patients with only mild impairment of CaSR function develop FHH. CaSR mutants that cause a more pronounced inhibition of wt-CaSR at physiological calcium concentrations may either lead to a neonatal phenotype (NHPT) or to FHH. Additional environmental and/or genetic factors such as allelic imbalance that critically reduce maternal-fetal calcium transfer may determine whether a particular genotype leads to NHPT instead of FHH. Calcium deficiency during fetal development combined with an exaggerated secondary hyperparathyroidism due to impaired overall CaSR function may then lead to neonatal manifestation as NHPT with serious metabolic bone disease, possibly also in patients with mutations that until now have only led to FHH. Although homozygous NSHPT and heterozygous NHPT have similarities in clinical phenotype, heterozygous NHPT shares pathophysiologic characteristics with FHH. An individual therapeutic approach to NHPT patients appears warranted.

Supplementary data

This is linked to the online version of the paper at http://dx.doi.org/10.1530/ EJE-16-0223.

Declaration of interest

We certify that no author has a conflict of interest that is relevant to the subject matter or materials included in this work.

\section{Funding}

This work was supported by institutional grants from the CharitéUniversity Medicine Berlin and from the Friedrich-Alexander University Erlangen-Nuremberg. 


\section{Author contribution statement}

Bernhard Mayr and Christof Schöfl conceived and designed the experiments. Markus Glaudo and Saskia Letz performed the experiments. Markus Glaudo, Saskia Letz and Bernhard Mayr analyzed the data. Bernhard Mayr, Christof Schöfl and Markus Glaudo wrote the paper. Marcus Quinkler, Ulrich Bogner, Ulf Elbelt, Christian J Strasburger, Dirk Schnabel, Erwin Lankes, Sandra Scheel, Joachim Feldkamp, Christine Haag, Egbert Schulze, Karin Frank-Raue and Friedhelm Raue contributed human genetic and clinical data.

\section{References}

1 Egbuna OI \& Brown EM. Hypercalcaemic and hypocalcaemic conditions due to calcium-sensing receptor mutations. Best Practice \& Research. Clinical Rheumatology 200822 129-148. (doi:10.1016/ j.berh.2007.11.006)

2 Thakker RV. Diseases associated with the extracellular calcium-sensing receptor. Cell Calcium 200435 275-282. (doi:10.1016/ j.ceca.2003.10.010)

3 Mayr BM, Schnabel D, Dörr HG \& Schöfl C. Genetics in endocrinology: Gain and loss of function mutations of the calcium sensing receptor and associated proteins: current treatment concepts. European Journal of Endocrinology 2016174 R189-R208. (doi:10.1530/ EJE-15-1028)

4 Nesbit MA, Hannan FM, Howles SA, Babinsky VN, Head RA, Cranston T, Rust N, Hobbs MR, Heath H 3rd \& Thakker RV. Mutations affecting G-protein subunit alpha11 in hypercalcemia and hypocalcemia. New England Journal of Medicine 2013368 2476-2486. (doi:10.1056/NEJMoa1300253)

5 Waller S, Kurzawinski T, Spitz L, Thakker R, Cranston T, Pearce S, Cheetham T \& van't Hoff WG. Neonatal severe hyperparathyroidism: genotype/phenotype correlation and the use of pamidronate as rescue therapy. European Journal of Pediatrics 2004163 589-594. (doi:10.1007/s00431-004-1491-0)

6 Wilhelm-Bals A, Parvex P, Magdelaine C \& Girardin E. Successful use of bisphosphonate and calcimimetic in neonatal severe primary hyperparathyroidism. Pediatrics 2012129 e812-e816. (doi:10.1542/ peds.2011-0128)

7 Atay Z, Bereket A, Haliloglu B, Abali S, Ozdogan T, Altuncu E, Canaff L, Vilaca T, Wong BY, Cole DE et al. Novel homozygous inactivating mutation of the calcium-sensing receptor gene (CASR) in neonatal severe hyperparathyroidism-lack of effect of cinacalcet. Bone 201464 102-107. (doi:10.1016/j.bone.2014.04.010)

8 Garcia Soblechero E, Ferrer Castillo MT, Jimenez Crespo B, Dominguez Quintero ML \& Gonzalez Fuentes C. Neonatal hypercalcemia due to a homozygous mutation in the calcium-sensing receptor: failure of cinacalcet. Neonatology 2013 104 104-108. (doi:10.1159/000350540)

9 Bai M, Pearce SH, Kifor O, Trivedi S, Stauffer UG, Thakker RV, Brown EM \& Steinmann B. In vivo and in vitro characterization of neonatal hyperparathyroidism resulting from a de novo, heterozygous mutation in the Ca2+-sensing receptor gene: normal maternal calcium homeostasis as a cause of secondary hyperparathyroidism in familial benign hypocalciuric hypercalcemia. Journal of Clinical Investigation 199799 88-96. (doi:10.1172/JCI119137)

10 Chattopadhyay N \& Brown EM. Calcium-Sensing Receptor. New York, NY, USA: Springer, 2003.

11 Rus R, Haag C, Bumke-Vogt C, Bähr V, Mayr B, Möhlig M, Schulze E, Frank-Raue K, Raue F \& Schöfl C. Novel inactivating mutations of the calcium-sensing receptor: the calcimimetic NPS R-568 improves signal transduction of mutant receptors. Journal of Clinical Endocrinology and Metabolism 200893 4797-4803. (doi:10.1210/jc.2008-1076)

12 Letz S, Rus R, Haag C, Dörr HG, Schnabel D, Möhlig M, Schulze E, Frank-Raue K, Raue F, Mayr B et al. Novel activating mutations of the calcium-sensing receptor: the calcilytic NPS-2143 mitigates excessive signal transduction of mutant receptors. Journal of Clinical Endocrinology and Metabolism 201095 E229-E233. (doi:10.1210/ jc.2010-0651)

13 Szczawinska D, Schnabel D, Letz S \& Schöfl C. A homozygous CaSR mutation causing a FHH phenotype completely masked by vitamin D deficiency presenting as rickets. Journal of Clinical Endocrinology and Metabolism 201499 E1146-E1153. (doi:10.1210/jc.2013-3593)

14 Letz S, Haag C, Schulze E, Frank-Raue K, Raue F, Hofner B, Mayr B $\&$ Schöfl C. Amino alcohol- (NPS-2143) and quinazolinone-derived calcilytics (ATF936 and AXT914) differentially mitigate excessive signalling of calcium-sensing receptor mutants causing Bartter syndrome type 5 and autosomal dominant hypocalcemia. PLOS ONE 20149 e115178. (doi:10.1371/journal.pone.0115178)

15 Wystrychowski A, Pidasheva S, Canaff L, Chudek J, Kokot F, Wiecek A $\&$ Hendy GN. Functional characterization of calcium-sensing receptor codon 227 mutations presenting as either familial (benign) hypocalciuric hypercalcemia or neonatal hyperparathyroidism. Journal of Clinical Endocrinology and Metabolism 200590 864-870. (doi:10.1210/jc.2004-1791)

16 Ho C, Conner DA, Pollak MR, Ladd DJ, Kifor O, Warren HB, Brown EM, Seidman JG \& Seidman CE. A mouse model of human familial hypocalciuric hypercalcemia and neonatal severe hyperparathyroidism. Nature Genetics 199511 389-394. (doi:10.1038/ ng1295-389)

17 Raue F \& Haag C. Familial hypocalciuric hypercalcemia. In Diseases of the Parathyroid Glands, ch. The Calcium-Sensing Receptor: Physiology and Pathophysiology, pp 78-80. Eds AA Licata \& EV Lerma. New York, NY, USA: Springer, 2012.

18 Kobayashi M, Tanaka H, Tsuzuki K, Tsuyuki M, Igaki H, Ichinose Y, Aya K, Nishioka N \& Seino Y. Two novel missense mutations in calcium-sensing receptor gene associated with neonatal severe hyperparathyroidism. Journal of Clinical Endocrinology and Metabolism 199782 2716-2719. (doi:10.1210/jcem.82.8.4135)

19 Fox L, Sadowsky J, Pringle KP, Kidd A, Murdoch J, Cole DE \& Wiltshire E. Neonatal hyperparathyroidism and pamidronate therapy in an extremely premature infant. Pediatrics 2007120 e1350-e1354. (doi:10.1542/peds.2006-3209)

20 Tonyushkina KN, O'Connor S \& Dunbar NS. A novel CaSR mutation presenting as a severe case of neonatal familial hypocalciuric hypercalcemia. International Journal of Pediatric Endocrinology 2012 2012 13. (doi:10.1186/1687-9856-2012-13)

21 Toke J, Czirjak G, Patocs A, Enyedi B, Gergics P, Csakvary V, Enyedi P $\&$ Toth $\mathrm{M}$. Neonatal severe hyperparathyroidism associated with a novel de novo heterozygous $\mathrm{R} 551 \mathrm{~K}$ inactivating mutation and a heterozygous A986S polymorphism of the calcium-sensing receptor gene. Clinical Endocrinology 200767 385-392. (doi:10.1111/ j.1365-2265.2007.02896.x)

22 Pearce SH, Trump D, Wooding C, Besser GM, Chew SL, Grant DB, Heath DA, Hughes IA, Paterson CR, Whyte MP et al. Calcium-sensing receptor mutations in familial benign hypercalcemia and neonatal hyperparathyroidism. Journal of Clinical Investigation 199596 2683-2692. (doi:10.1172/JCI118335)

23 Nyweide K, Feldman KW, Gunther DF, Done S, Lewis C \& Van Eenwyk C. Hypocalciuric hypercalcemia presenting as neonatal rib fractures: a newly described mutation of the calcium-sensing receptor gene. Pediatric Emergency Care 200622 722-724. (doi:10.1097/ 01.pec.0000238747.19477.d3)

24 Kovacs CS. Bone development and mineral homeostasis in the fetus and neonate: roles of the calciotropic and phosphotropic hormones. Physiological Reviews 201494 1143-1218. (doi:10.1152/ physrev.00014.2014)

25 Kovacs CS, Ho-Pao CL, Hunzelman JL, Lanske B, Fox J, Seidman JG, Seidman CE \& Kronenberg HM. Regulation of murine fetal-placental calcium metabolism by the calcium-sensing receptor. Journal of Clinical Investigation 1998101 2812-2820. (doi:10.1172/JCI2940) 
26 Fisher MM, Cabrera SM \& Imel EA. Successful treatment of neonatal severe hyperparathyroidism with cinacalcet in two patients. Endocrinology, Diabetes \& Metabolism Case Reports 20152015150040. (doi:10.1530/edm-15-0040)

27 Wilkinson H \& James J. Self limiting neonatal primary hyperparathyroidism associated with familial hypocalciuric hypercalcaemia. Archives of Diseases in Childhood 199369 319-321. (doi:10.1136/adc.69.3_Spec_No.319)

28 Page LA \& Haddow JE. Self-limited neonatal hyperparathyroidism in familial hypocalciuric hypercalcemia. Journal of Pediatrics 1987111 261-264. (doi:10.1016/S0022-3476(87)80083-5)

29 Harris SS \& D'Ercole AJ. Neonatal hyperparathyroidism: the natural course in the absence of surgical intervention. Pediatrics $1989 \mathbf{8 3}$ 53-56.

30 Christensen SE, Nissen PH, Vestergaard P, Heickendorff L, Brixen K $\&$ Mosekilde L. Discriminative power of three indices of renal calcium excretion for the distinction between familial hypocalciuric hypercalcaemia and primary hyperparathyroidism: a follow-up study on methods. Clinical Endocrinology 200869 713-720. (doi:10.1111/ j.1365-2265.2008.03259.x)

31 Al-Khalaf FA, Ismail A, Soliman AT, Cole DE \& Ben-Omran T. Neonatal severe hyperparathyroidism: further clinical and molecular delineation. European Journal of Pediatrics 2011170 625-631. (doi:10.1007/s00431-010-1335-z)

32 Reh CM, Hendy GN, Cole DE \& Jeandron DD. Neonatal hyperparathyroidism with a heterozygous calcium-sensing receptor (CASR) R185Q mutation: clinical benefit from cinacalcet. Journal of Clinical Endocrinology and Metabolism 201196 E707-E712. (doi:10.1210/jc.2010-1306)

33 Gannon AW, Monk HM \& Levine MA. Cinacalcet monotherapy in neonatal severe hyperparathyroidism: a case study and review. Journal of Clinical Endocrinology and Metabolism 201499 7-11. (doi:10.1210/jc.2013-2834)

34 Obermannova B, Banghova K, Sumnik Z, Dvorakova HM, Betka J, Fencl F, Kolouskova S, Cinek O \& Lebl J. Unusually severe phenotype of neonatal primary hyperparathyroidism due to a heterozygous inactivating mutation in the CASR gene. European Journal of Pediatrics 2009168 569-573. (doi:10.1007/s00431-008-0794-y)

35 Dezateux CA, Hyde JC, Hoey HM, O'Riordan JL, Spitz L, Taylor GW \& Grant DB. Neonatal hyperparathyroidism. European Journal of Pediatrics 1984142 135-136. (doi:10.1007/BF00445595)
36 Pollak MR, Brown EM, Chou YH, Hebert SC, Marx SJ, Steinmann B, Levi T, Seidman CE \& Seidman JG. Mutations in the human $\mathrm{Ca}(2+)-$ sensing receptor gene cause familial hypocalciuric hypercalcemia and neonatal severe hyperparathyroidism. Cell 199375 1297-1303. (doi:10.1016/0092-8674(93)90617-Y)

37 Marx SJ, Spiegel AM, Brown EM \& Aurbach GD. Family studies in patients with primary parathyroid hyperplasia. American Journal of Medicine 197762 698-706. (doi:10.1016/00029343(77)90873-7)

38 Sarli M, Fradinger E \& Zanchetta J. [Hypocalciuric hypercalcemia due to de novo mutation of the calcium sensing receptor]. Medicina (B Aires) 200464 337-339.

39 Christie P, Curley A, Nesbit MA, Harding B, Bowl M \& Thakker R. Characterisation of 25 calcium-sensing receptor mutations in disorders of calcium homeostasis. In Society for Endocrinology BES 2007. Birmingham, UK, 2007.

40 Chou YH, Pollak MR, Brandi ML, Toss G, Arnqvist H, Atkinson AB, Papapoulos SE, Marx S, Brown EM, Seidman JG et al. Mutations in the human $\mathrm{Ca}(2+)$-sensing-receptor gene that cause familial hypocalciuric hypercalcemia. American Journal of Human Genetics $1995 \mathbf{5 6}$ 1075-1079.

41 Chou YH, Brown EM, Levi T, Crowe G, Atkinson AB, Arnqvist HJ, Toss G, Fuleihan GE, Seidman JG \& Seidman CE. The gene responsible for familial hypocalciuric hypercalcemia maps to chromosome $3 \mathrm{q}$ in four unrelated families. Nature Genetics 19921 295-300. (doi:10.1038/ ng0792-295)

42 Lietman SA, Tenenbaum-Rakover Y, Jap TS, Yi-Chi W, De-Ming Y, Ding C, Kussiny N \& Levine MA. A novel loss-of-function mutation, Gln459Arg, of the calcium-sensing receptor gene associated with apparent autosomal recessive inheritance of familial hypocalciuric hypercalcemia. Journal of Clinical Endocrinology and Metabolism 2009 94 4372-4379. (doi:10.1210/jc.2008-2484)

43 Gunganah K, Grossman A \& Druce M. Recurrent pancreatitis in a patient with familial hypocalciuric hypercalcaemia treated successfully with cinacalcet. Endocrinology, Diabetes \& Metabolism Case Reports 20142014 140050. (doi:10.1530/edm-14-0050)

44 Aparicio Lopez C, Anton-Martin P, Gil-Fournier B, Ramiro-Leon S, Perez-Nanclares G, Perez de Nanclares G, Martinez Menendez B \& Castano L. Familial hypocalciuric hypercalcemia: new mutation in the CASR gene converting valine 697 to methionine. European Journal of Pediatrics 2012171 147-150. (doi:10.1007/s00431-011-1504-8)

Received 14 March 2016

Revised version received 22 August 2016

Accepted 30 August 2016 